\title{
Safety and efficacy of everolimus in gastrointestinal and pancreatic neuroendocrine tumors after ${ }^{177}$ Lu-octreotate
}

\author{
Kimberly Kamp', Brenda Gumz ${ }^{3}$, Richard A Feelders', Dik J Kwekkeboom², \\ Gregory Kaltsas ${ }^{4}$, Frederico P Costa ${ }^{3}$ and Wouter W de Herder ${ }^{1}$ \\ ${ }^{1}$ Sector of Endocrinology, Department of Internal Medicine ${ }^{2}$ Department of Nuclear Medicine, \\ Erasmus Medical Center, 's-Gravendijkwal 230, 3015 CE Rotterdam, The Netherlands \\ ${ }^{3}$ Centro de Oncologia, Hospital Sírio Libanês, São Paulo, Brazil \\ ${ }^{4}$ Department of Pathophysiology, National University of Athens, Athens, Greece
}

Correspondence should be addressed to $W$ W de Herder Email

w.w.deherder@erasmusmc.nl

\begin{abstract}
Although ${ }^{177}$ Lu-octreotate is an effective treatment for patients with gastroenteropancreatic neuroendocrine tumors (GEP-NETs), some patients will fail or develop disease progression necessitating further treatment. We examined whether the safety and efficacy of everolimus after prior treatment with ${ }^{177}$ Lu-octreotate is different from the published safety profile of everolimus in GEP-NETs. In this multicenter study, 24 GEP-NET patients were included. Adverse events were assessed according to the National Cancer Institute Common Terminology Criteria for Adverse Events (CTCAE), version 3.0. Tumor response was measured according to the Response Evaluation Criteria in Solid Tumors (RECIST), version 1.0. Major clinical adverse events (grade 3 or 4) during treatment with everolimus were hyperglycemia $(20.8 \%)$, fatigue $(8.3 \%)$, thrombocytopenia (8.3\%), and elevated alanine transaminase levels (8.3\%). By radiological review, there were four partial responses (16.7\%), five patients $(62.5 \%)$ with stable disease, and three patients $(12.5 \%)$ with progressive disease. For two patients (8.3\%), no data on tumor response were available. Median progression-free survival (PFS) was 13.1 months $(95 \% \mathrm{Cl}, 11.5-21.2)$. Median PFS of the current study was longer when compared with the RADIANT-3 trial (13.1 vs 11.4 months) and shorter when compared with the RADIANT-1 trial (13.1 vs 16.7 months). In conclusion, the safety profile of everolimus is not influenced by previous treatment with peptide receptor radiotherapy.
\end{abstract} Key Words

\section{Introduction}

Neuroendocrine tumors (NETs) form a heterogeneous group of relatively rare neoplasms that originate from different types of neuroendocrine cells (Modlin et al. 2008). The incidence and prevalence of gastroenteropancreatic NETs (GEP-NETs) have shown a remarkable increase over the past three decades. The United States Surveillance Epidemiology and End Results (SEER) database and several other European databases currently estimate the GEP-NET incidence at between 2.5 and 6.2 cases/100 000 population (Fraenkel et al. 2012). Whether 
this is a true increase in incidence, the result of an increased use of imaging techniques, or a combination of the two has not been established yet.

Despite the constantly increasing incidence and prevalence of GEP-NETs, treatment options remain limited. Clinical symptomatology in patients with functioning well-differentiated GEP-NETs has already been successfully treated with somatostatin analogs for more than 25 years. Furthermore, in patients with metastatic NETs of the small intestinal tract, treatment with octreotide long-acting repeatable (LAR) i.m. $30 \mathrm{mg} / \mathrm{month}$ resulted in an increase in time to progression from 6 to 16.3 months when compared with placebo (Rinke et al. 2009).

However, upon progression, peptide receptor radionuclide therapy (PRRT) with radiolabeled somatostatin analogs has been shown to be effective regarding tumor control (Bergsma et al. 2012). Although ${ }^{177} \mathrm{Lu}$-octreotate is being increasingly used, there are limitations to its use and some patients who initially responded may became refractory after a certain number of treatment cycles necessitating further treatment.

Everolimus, an mTOR inhibitor, has been shown to be a promising anti-tumor agent for patients with welldifferentiated (WHO grades 1 and 2) GEP-NETs with progressive disease (PD), with a well-established safety profile (Yao et al. 2008, 2010, 2011, Pavel et al. 2011). In the randomized phase III RADIANT-3 study, everolimus therapy was associated with a 2.4-fold improvement in median progression-free survival (PFS) in patients with progressive pancreatic NETs (pNETs) compared with placebo. Median PFS was 11 months in the everolimus arm compared with 4.6 months in the placebo arm (HR, 0.35; 95\% CI, 0.27-0.45; log-rank test, $P<0.0001$; Yao et al. 2011).

In another randomized phase III RADIANT-2 study in advanced mainly gastrointestinal (GI) NETs associated with carcinoid syndrome, it was demonstrated that everolimus plus octreotide LAR provided clinically meaningful 5.1-month improvement in PFS, which was not statistically significant, when compared with patients receiving placebo plus octreotide LAR (Pavel et al. 2011).

However, there are currently no data regarding the toxicity and efficacy of everolimus after prior treatment with ${ }^{177} \mathrm{Lu}$-octreotate radionuclide therapy. The aim of this study was to investigate whether the safety and efficacy profile of everolimus in patients who have progressed after ${ }^{177} \mathrm{Lu}$-octreotate radionuclide therapy is different from the already known profile.

\section{Subjects and methods}

\section{Patients}

All patients with well-differentiated or moderately differentiated (grades 1 and 2) GEP-NETs that received any dose (10 or $5 \mathrm{mg}$ ) of everolimus at least once immediately after documented progression following ${ }^{177} \mathrm{Lu}$-octreotate therapy were included in this multicenter study. We retrospectively studied 24 patients with GEP-NETs, treated in three institutions in The Netherlands, Brazil, and Greece between 2010 and 2012. We retrospectively screened 30 patients for inclusion in this study. Patients were eligible to be included in the study if they had a grades 1 and 2 GEP-NETs, a WHO performance status of 2 or less, hemoglobin levels of $\geq 8.9 \mathrm{~g} / \mathrm{dl}$, and a creatinine clearance above $50 \mathrm{ml} / \mathrm{min}$ at baseline. Other prior antitumor therapies were not considered to be exclusion criteria. Six patients were excluded from this study: one patient had a primary lung NET, two patients had a WHO performance status of 3, two patients had a hemoglobin of $<8.9 \mathrm{~g} / \mathrm{dl}$, and one patient whose follow-up data were missing.

According to the grading system proposed by the European Neuroendocrine Tumor Society (ENETS) WHO, grade $1(\mathrm{Ki}-67 \leq 2 \%)$ and grade 2 (Ki-67 2-20\%) tumors are regarded as well-differentiated and moderately differentiated tumors (Rindi et al. 2006, 2007). At baseline, all patients had radiological documentation of $\mathrm{PD}$ according to Response Evaluation Criteria in Solid Tumors (RECIST), version 1.0 (Therasse et al. 2000).

All patients had given informed consent to participate in the ${ }^{177} \mathrm{Lu}$-octreotate therapy series. Furthermore, the study was conducted in accordance with Good Clinical Practice principles and applicable local regulations.

\section{Safety and efficacy assessments}

The primary end point of this study was the retrospective evaluation of the safety profile of everolimus in patients previously treated with ${ }^{177} \mathrm{Lu}$-octreotate radionuclide therapy. Patients were historically assessed for safety parameters at baseline, including previously reported adverse events during ${ }^{177} \mathrm{Lu}$-octreotate radionuclide therapy and specific laboratory values. Baseline was defined as last documented parameters prior to initiation of everolimus ( 10 or $5 \mathrm{mg}$ ) therapy. All patients were seen in clinical settings at 40-day intervals with laboratory tests (including biomarkers), physical examination, and toxicity assessment. Tumor measurements (assessed by computed tomography (CT) and/or magnetic resonance

Published by Bioscientifica Ltd. 
imaging) were performed at baseline and every 120 days unless there were any new symptoms. Chest imaging (chest X-ray or chest CT) was performed to document or exclude interstitial lung disease in all centers. These follow-up intervals (1-3 months) were taken into consideration retrospectively as documented by each individual institution. Follow-up intervals were similar to the intervals in the RADIANT-3 study (Yao et al. 2011).

Adverse events were assessed according to the National Cancer Institute Common Terminology Criteria for Adverse Events (CTCAE), version 3.0 (http://ctep. cancer.gov/protocolDevelopment/electronic_applications/docs/ctcaev3.pdf). Doses of everolimus were reduced and/or dose intervals were increased (5 $\mathrm{mg}$ daily or $5 \mathrm{mg}$ every other day) when patients had clinically significant adverse events that were considered to be related to the treatment with everolimus. Treatment continued until the development of an unacceptable adverse event, $\mathrm{PD}$, or death.

Secondary end points included PFS, objective response rate, duration of response, symptom control, and tumor marker control. All patients were assessed for efficacy according to RECIST, version 1.0 (Therasse et al. 2000). PFS was documented according to RECIST, version 1.0 and defined as the time from initiation of everolimus therapy to the first radiological documentation of PD or death from any cause.

\section{Statistical analyses}

PFS was analyzed using Kaplan-Meier methods. Calculations were performed using Statistical Package for Social Sciences (SPSS) software, V.20.0.

\section{Results}

\section{Patients and treatment}

Between September 2010 and July 2012, a total of 24 NET patients - 13 men and 11 women - from three centers in three countries were initiated on everolimus after tumor progression following ${ }^{177} \mathrm{Lu}$-octreotate radionuclide therapy. The median interval between last ${ }^{177} \mathrm{Lu}$-octreotate therapy and start of everolimus treatment was 18.7 months (range 2.9-47.6 months). The demographic and baseline clinical characteristics of the 24 patients are listed in Table 1. Patients had a median age of 60.0 years (range 32.2-65.9 years) at start of treatment with everolimus. The median interval between the initial diagnosis of the NET and the initiation of everolimus therapy was 64.2 months
Table 1 Demographic and baseline clinical characteristics of 24 patients with GEP-NETs treated with everolimus after ${ }^{177}$ Lu-DOTA ${ }^{0}$-Tyr ${ }^{3}$-octreotate therapy failure

\begin{tabular}{|c|c|c|}
\hline Characteristics & $n$ & $\%$ \\
\hline Total & 24 & 100 \\
\hline \multicolumn{3}{|l|}{ Gender } \\
\hline Male & 13 & 54.2 \\
\hline Female & 11 & 45.8 \\
\hline \multicolumn{3}{|l|}{ Age (years) } \\
\hline$<50$ & 8 & 33.3 \\
\hline $50-69$ & 14 & 58.3 \\
\hline$>70$ & 2 & 8.4 \\
\hline \multicolumn{3}{|l|}{ Race } \\
\hline Caucasian & 23 & 95.8 \\
\hline Asian & 1 & 4.2 \\
\hline \multicolumn{3}{|l|}{ WHO performance status } \\
\hline 0 & 5 & 20.8 \\
\hline 1 & 17 & 70.8 \\
\hline 2 & 2 & 8.4 \\
\hline \multicolumn{3}{|l|}{ Primary localization } \\
\hline Pancreas & 18 & 75.0 \\
\hline Non-functioning & 16 & 66.6 \\
\hline Glucagonoma & 1 & 4.2 \\
\hline VIPoma & 1 & 4.2 \\
\hline Duodenum & 1 & 4.2 \\
\hline Small intestine & 2 & 8.4 \\
\hline Colon & 1 & 4.2 \\
\hline Rectum & 1 & 4.2 \\
\hline $\begin{array}{l}\text { Cancer of unknown } \\
\text { primary }\end{array}$ & 1 & 4.2 \\
\hline \multicolumn{3}{|l|}{ Metastasis localization } \\
\hline Liver & 22 & 91.7 \\
\hline Bone & 7 & 29.2 \\
\hline Lymph node & 12 & 50.0 \\
\hline \multicolumn{3}{|l|}{ Tumor grade } \\
\hline Well differentiated & 7 & 29.2 \\
\hline Moderately differentiated & 14 & 58.3 \\
\hline Unknown & 3 & 12.5 \\
\hline \multicolumn{3}{|l|}{ ENETS stage } \\
\hline $\mathrm{IIb}$ & 1 & 4.2 \\
\hline IV & 23 & 95.8 \\
\hline
\end{tabular}

(range 9.9-273.5 months). The median follow-up of the study population was 11.0 months (range 1.9-28.9 months). pNETs (75\%) were the most common primary tumors when compared with NETs arising in the digestive tract $(25 \%)$. Metastases were demonstrated in 23 patients (95.8\%), main localizations were liver (91.7\%) and lymph nodes $(50 \%)$. The majority of patients $(95.8 \%)$ included in our study were diagnosed with ENETS stage IV disease (Rindi et al. 2006, 2007). Information on tumor grading was available for 21 patients (87.5\%): 7 (29.2\%) were welldifferentiated (grade 1 ) and 14 (58.3\%) were moderately differentiated (grade 2).

Information regarding previous treatment regimens and interventions, responses and duration of responses is listed in Tables 2 and 3. Patients were treated with a median dose of ${ }^{177} \mathrm{Lu}$-octreotate of $37.0 \mathrm{GBq}$

Published by Bioscientifica Ltd. 
Table 2 Previous treatments: multicenter $(n=24)$

\begin{tabular}{|c|c|c|}
\hline Previous treatments & $n$ & $\%$ \\
\hline Total patients & 24 & 100 \\
\hline${ }^{177}$ Lu-octreotate (GBq) & 24 & 100 \\
\hline $0-10$ & 1 & 4.2 \\
\hline $10-20$ & 3 & 12.5 \\
\hline $20-30$ & 4 & 16.7 \\
\hline $30-40$ & 2 & 8.3 \\
\hline $40-50$ & 6 & 25.0 \\
\hline $50-60$ & 2 & 8.3 \\
\hline $60-70$ & 1 & 4.2 \\
\hline Not available & 5 & 20.8 \\
\hline $\begin{array}{l}\text { Median administered dose in } \\
\text { GBq (range) }\end{array}$ & \multicolumn{2}{|c|}{$37.0(7.4-60.1)$} \\
\hline Chemotherapy & 8 & 33.3 \\
\hline Xelox & 3 & 12.5 \\
\hline Interferon- $\alpha$ & 1 & 4.2 \\
\hline 5FU-STZ & 1 & 4.2 \\
\hline Cisplatin-etoposide & 1 & 4.2 \\
\hline Bevacizumab & 1 & 4.2 \\
\hline $\begin{array}{l}\text { Cisplatin-etoposide + cisplatin- } \\
\text { irinotecan +VAC }\end{array}$ & 1 & 4.2 \\
\hline Surgery & 11 & 45.8 \\
\hline Major (curative intent) & 6 & 25.0 \\
\hline Palliative & 5 & 20.8 \\
\hline Somatostatin analog use & 14 & 58.3 \\
\hline Octreotide LAR 20 mg/4 weeks & 4 & 16.7 \\
\hline Octreotide LAR $30 \mathrm{mg} / 4$ weeks ${ }^{a}$ & 9 & 37.5 \\
\hline Short-acting octreotide & 1 & 4.2 \\
\hline
\end{tabular}

Xelox, capecitabine plus oxaliplatin; 5FU-STZ, 5 fluorouracil-streptozotocin; VAC, vincristine-adriamycin-cyclophosphamide; LAR, long-acting repeatable.

ane patient used a combination of octreotide LAR $30 \mathrm{mg} / 4$ weeks and short-acting octreotide.

(range 7.4-60.1 GBq) divided over one to eight therapy cycles. Other previous treatments and interventions were surgery (45.8\%), cytotoxic chemotherapy (33.3\%), and somatostatin analogs (58.3\%). All 14 patients receiving somatostatin analogs $(58.3 \%)$ continued treatment during treatment with everolimus in our study.
Twenty-two patients started with a daily dose of $10 \mathrm{mg}$ everolimus and two patients started with a daily dose of $5 \mathrm{mg}$. Dose adjustments were required in $16.7 \%$ of the patients (two temporary reduction to $5 \mathrm{mg}(8.3 \%)$ and two definite reductions to $5 \mathrm{mg}(8.3 \%))$. Temporary interruptions were required in $29.2 \%$ of the patients. The median cumulative time of treatment with everolimus was 10.2 months (range 0.6-25.4 months). At the time the analysis was performed, treatment was ongoing for $45.8 \%$ of the patients. The primary reasons for discontinuation of treatment included radiological confirmed PD (29.2\%), development of an unacceptable toxic adverse event (16.7\%), and death (8.3\%).

\section{Safety}

Most adverse events in the current study were grade 1 or 2 . Table 4 shows the adverse events of everolimus and ${ }^{177} \mathrm{Lu}$-octreotate therapies in patients with metastatic well-differentiated and moderately differentiated GEPNETs compared with that reported in the RADIANT-3 trial (Yao et al. 2011) and the Rotterdam ${ }^{177} \mathrm{Lu}$-octreotate trial (Kwekkeboom et al. 2008). The newly occurring adverse events after initiation of everolimus therapy in this study and those in patients treated with everolimus after failure of cytotoxic chemotherapy (Yao et al. 2010) are also listed in Table 4.

Most common new clinical adverse events occurring after initiation of everolimus therapy in this study were oromucosal sequelae $(41.7 \%)$, pneumonitis $(37.5 \%)$, fatigue $(33.3 \%)$, peripheral edema (25\%), and rash $(25 \%)$. Drug-induced pneumonitis was mainly a radiological finding (1-9 months after initiation of everolimus therapy) without clinical consequences and did not lead to interruption or discontinuation of everolimus therapy.

Table 3 Response and duration of response in previous treatments ( ${ }^{177}$ Lu-octreotate and chemotherapy): multicenter ( $\left.n=24\right)$

\begin{tabular}{|c|c|c|c|c|c|c|c|c|c|c|c|c|}
\hline & & & & & & Best re & ons & & & & & \\
\hline & Total & atients & & & & & & & & & Duration & response \\
\hline & $n$ & $\%$ & $n$ & $\%$ & $n$ & $\%$ & $n$ & $\%$ & $n$ & $\%$ & $\begin{array}{l}\text { Median } \\
\text { (months) }\end{array}$ & $\begin{array}{c}\text { Range } \\
\text { (months) }\end{array}$ \\
\hline${ }^{177}$ Lu-octreotate & & & & & & & & & & & & \\
\hline $\begin{array}{l}\text { Cycles } 1-4 \\
\text { Additional }{ }^{177} \text { Lu-octreotate }\end{array}$ & 24 & 100 & 8 & 33.3 & 14 & 58.3 & 1 & 4.2 & 1 & 4.2 & 25.9 & 0-98.8 \\
\hline Cycles $5,5-6,5-7^{a}$ & 11 & 45.8 & 0 & 0.0 & 10 & 41.7 & 1 & 4.2 & 0 & 0.0 & 26.5 & 0-45.4 \\
\hline Cycles 7-8 & 3 & 12.5 & 1 & 4.2 & 2 & 8.3 & 0 & 0.0 & 0 & 0.0 & 19.2 & $14.8-21.8$ \\
\hline Chemotherapy & & & & & & & & & & & & \\
\hline 1 Regimen & 7 & 29.2 & 1 & 4.2 & 3 & 12.5 & 2 & 8.3 & 1 & 4.2 & 3.5 & $0-56$ \\
\hline$>1$ Prior regimen $^{\mathrm{b}}$ & 1 & 4.2 & 0 & 0.0 & 1 & 4.2 & 0 & 0.0 & 0 & 0.0 & NA & NA \\
\hline
\end{tabular}

NA, not available.

${ }^{\text {aCCycle }} 5(n=1)$, cycles 5-6 $(n=9)$, and cycles 5-7 $(n=1)$.

bPatients had already received one regimen of chemotherapy.

http://erc.endocrinology-journals.org DOI: 10.1530/ERC-13-0254
(C) 2013 Society for Endocrinology Printed in Great Britain
Published by Bioscientifica Ltd 
Table 4 Adverse events for everolimus and ${ }^{177}$ Lu-DOTA ${ }^{0}-$ Tyr $^{3}$-octreotate therapies in patients with metastatic well-differentiated or moderately differentiated GEP-NETs as reported in RADIANT-3 and ${ }^{177}$ Lu-DOTA ${ }^{0}$-Tyr ${ }^{3}$-octreotate trials. This table includes the adverse events for everolimus after failure of cytotoxic chemotherapy and this study

\begin{tabular}{|c|c|c|c|c|c|c|c|c|}
\hline \multirow[t]{2}{*}{ Treatment } & \multicolumn{2}{|c|}{$\begin{array}{l}\text { Everolimus } \\
\qquad(n=207)\end{array}$} & \multicolumn{2}{|c|}{$\begin{array}{c}\text { 177 Lu-octreotate }^{(n=504)} \\
\text { (n=5) }\end{array}$} & \multicolumn{2}{|c|}{$\begin{array}{c}\text { Everolimus post- } \\
\text { chemo } \\
(n=115)\end{array}$} & \multicolumn{2}{|c|}{ 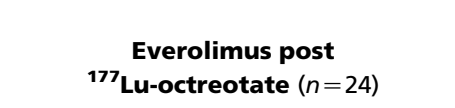 } \\
\hline & $\begin{array}{l}\text { All grades } \\
(\%)\end{array}$ & $\begin{array}{l}\text { Grade } 3 / 4 \\
(\%)\end{array}$ & $\begin{array}{l}\text { All grades } \\
(\%)\end{array}$ & $\begin{array}{l}\text { Grade } 3 / 4 \\
(\%)\end{array}$ & $\begin{array}{l}\text { All grades } \\
(\%)\end{array}$ & $\begin{array}{l}\text { Grade } 3 / 4 \\
(\%)\end{array}$ & $\begin{array}{c}\text { All grades } \\
\text { (baseline/new) (\%) }\end{array}$ & $\begin{array}{c}\text { Grade } 3 / 4 \\
\text { (baseline/new) (\%) }\end{array}$ \\
\hline \multicolumn{9}{|l|}{ Adverse event } \\
\hline Oral problems ${ }^{a}$ & 64 & 7 & NR & NR & 45.2 & 4.3 & 41.7 & 4.2 \\
\hline Rash & 49 & $<1$ & NR & NR & 40 & 0.9 & 25 & 4.2 \\
\hline Diarrhea & 34 & 3 & NR & NR & 39.1 & 3.5 & 4.2 & 4.2 \\
\hline Fatigue & 31 & 2 & NR & NR & 31.3 & 4.3 & 33.3 & 8.3 \\
\hline Infections ${ }^{b}$ & 23 & 2 & NR & NR & NR & NR & 8.3 & 0 \\
\hline Nausea & 20 & 2 & 25 & 0 & 29.6 & 0.9 & 4.2 & 0 \\
\hline Peripheral edema & 20 & $<1$ & NR & NR & 14.8 & 0 & 25 & 0 \\
\hline Decreased appetite & 20 & 0 & NR & NR & NR & NR & 4.2 & 0 \\
\hline Headache & 19 & 0 & NR & NR & 21.7 & 0 & 4.2 & 0 \\
\hline Dysgeusia & 17 & 0 & NR & NR & 10.4 & 0 & 16.7 & 0 \\
\hline Epistaxis & 17 & 0 & NR & NR & NR & NR & 16.7 & 4.2 \\
\hline Pulmonic ${ }^{c}$ & 17 & 2 & NR & NR & 6.1 & 0 & 37.5 & 0 \\
\hline Weight loss & 16 & 0 & NR & NR & 14.8 & 0 & ID & ID \\
\hline Vomiting & 15 & 0 & 10 & 0 & 17.4 & 0 & 4.2 & 0 \\
\hline Pruritus & 15 & 0 & NR & NR & 12.2 & 0 & 8.3 & 4.2 \\
\hline Asthenia & 13 & 1 & NR & NR & 14.8 & 5.2 & 4.2 & 0 \\
\hline Nail disorder & 12 & $<1$ & NR & NR & NR & NR & 8.3 & 0 \\
\hline Cough & 11 & 0 & NR & NR & NR & NR & 12.5 & 0 \\
\hline Pyrexia & 11 & 0 & NR & NR & NR & NR & 12.5 & 0 \\
\hline Dry skin & 10 & 0 & NR & NR & 9.6 & 0 & 16.7 & 4.2 \\
\hline Abdominal pain & NR & NR & 10 & 0 & NR & NR & 0 & 0 \\
\hline Hormone crisis & NR & NR & 1 & 1 & NR & NR & NR & NR \\
\hline Hair loss & NR & NR & 62 & 0 & NR & NR & NR & NR \\
\hline \multicolumn{9}{|l|}{ Laboratory event } \\
\hline Anemia & 17 & 6 & 0.4 & $0.3 / 0.1$ & 13 & 4.3 & (B:45.8) 20.9 & $(B: 0) 0$ \\
\hline Thrombocytopenia & 13 & 4 & 2.7 & $1.9 / 0.8$ & 7.8 & 2.6 & (B:33.3) 16.7 & $(B: 0) 8.3$ \\
\hline Leukopenia & NR & NR & 1.5 & $1.4 / 0.1$ & 7 & 4.3 & $(B: 20.8) 20.9$ & $(B: 0) 4.2$ \\
\hline Myelodysplastic syndrome & NR & NR & 0.8 & 0.8 & NR & NR & NR & NR \\
\hline Hyperglycemia & 13 & 5 & NR & NR & 13 & 4.3 & $(B: 25) 25.0$ & $(B: 8.3) 12.5$ \\
\hline Hypercholesterolemia & NR & NR & NR & NR & NR & NR & (B:4.2) 16.6 & $(\mathrm{~B}: 0) 0$ \\
\hline ALT & NR & NR & 1.0 & 0.6 & NR & NR & $(B: 41.7) 12.5$ & $(B: 0) 8.3$ \\
\hline AST & NR & NR & 1.0 & 0.6 & NR & NR & $(B: 45.8) 25.0$ & $(B: 0) 4.2$ \\
\hline Kidney failure & NR & NR & NR & 0.4 & NR & NR & $(B: 29.2) 8.3$ & $(\mathrm{~B}: 0) 4.2$ \\
\hline
\end{tabular}

NR, not recorded; ID, insufficient data, not routinely checked; (B:..), baseline before start everolimus; ALT, alanine transaminase; AST, aspartate transaminase.

Included in this category are stomatitis, aphthous stomatitis, mouth ulceration, and tongue ulceration.

${ }^{b}$ All types of infections are included.

Included in this category are pneumonitis, interstitial lung disease, lung infiltrations, and pulmonary fibrosis.

The most common grade 3 or 4 drug-related adverse events that occurred after initiation of everolimus therapy were hyperglycemia $(12.5 \%)$, fatigue $(8.3 \%)$, thrombocytopenia $(8.3 \%)$, and elevated alanine transaminase levels (8.3\%).

\section{Efficacy}

The median PFS in our study was 13.1 months (95\% CI 11.5-21.2; Fig. 1). Best objective response rates were a partial response (PR) in $16.7 \%$ of the patients and stable disease (SD) in $62.5 \%$ of the patients whereas $12.5 \%$ of the patients continued having PD.

\section{Discussion}

In this retrospective study, we evaluated the safety and efficacy profile of everolimus in well-differentiated or moderately differentiated (grades 1 and 2) GEP-NET patients with documented disease progression after prior treatment 


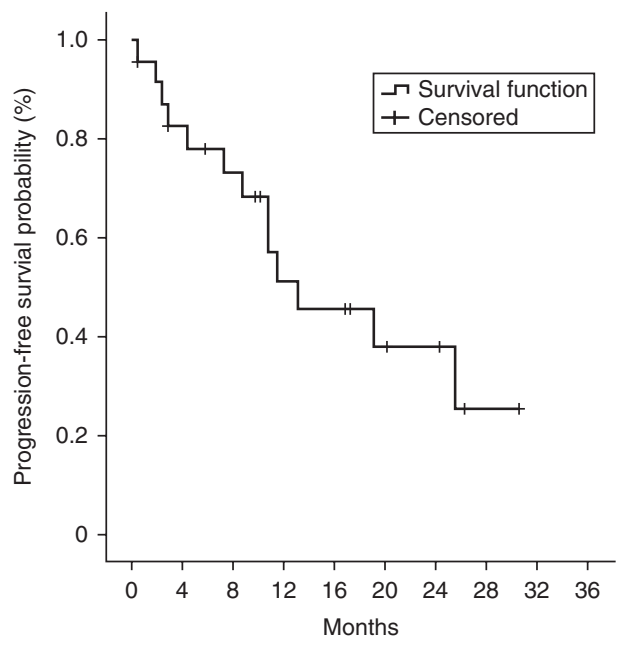

Figure 1

Progression-free survival: Kaplan-Meier curve, multicenter $(n=24)$.

with ${ }^{177} \mathrm{Lu}$-octreotate. The median interval between the last ${ }^{177} \mathrm{Lu}$-octreotate therapy and start of everolimus treatment was 18.7 months. Even 12 months after the last cycle of ${ }^{177} \mathrm{Lu}$-octreotate, tumor responses can be observed (Kwekkeboom DJ, personal communication 2012). This international, multicenter study is, to our knowledge, the first study in which the occurrence of grades $1-4$ toxicities in patients treated with everolimus after peptide receptor radiotherapy was compared with the published safety profile of everolimus in GEP-NETs. Our findings with respect to safety were consistent with the known safety profile of everolimus established in earlier phase II and III studies, and most adverse events were either grade 1 or 2 (Yao et al. 2008, 2010, 2011, Pavel et al. 2011). However, our results are not directly comparable with the results of prospective trials (RADIANT-trails) due to different study designs.

The most common drug-related adverse events in our study were oromucosal sequelae, which generally resolved during treatment. Other common and frequent adverse events were pulmonary (non-infectious pneumonitis and interstitial lung disease), fatigue, peripheral edema, and rash. Most adverse events were easily manageable, as evidenced by the low rate of discontinuation of treatment (16.7\%).

We consider our patients to be a heavily pretreated group. The majority of our patients had received prior treatment with somatostatin analogs, chemotherapy, or a combination of those therapies. Somatostatin analog treatment was continued in all patients during treatment with everolimus in our study. All patients received treatment with ${ }^{177} \mathrm{Lu}$-octreotate and it is commonly known that with this therapy high cumulative dosages can cause serious side effects, including kidney failure, cytopenias, or myelodysplastic syndrome (MDS; Bergsma et al. 2012). With this knowledge, drug-related kidney failure was monitored in this study. However, data from the Rotterdam ${ }^{177}$ Lu-octreotate trial show that serious hematological toxicity, MDS, and liver toxicity are relatively rare and occur in $\sim 1 \%$ of the patients (Kwekkeboom et al. 2008, van Essen et al. 2010). Everolimus therapy can be associated with mild lymphopenia and neutropenia. In the current study, no MDS was reported, only two patients had a grades 1 and 2 infection and no grade 3 or 4 drugrelated infections were reported. Grade 3 or 4 drug-related kidney failure and elevated transaminases occurred in $4.2 \%$ of the patients. The kidney failure can be most probably explained by the combined effect of the two therapies. Therefore, we can conclude that everolimus is well tolerated with regard to bone marrow function if PRRT has not lead to ongoing bone marrow suppression.

PFS results of this study are similar to the prolonged PFS that was reported in earlier phase II and III randomized trials, which included patients with advanced pNETs and gastrointestinal NETs (Yao et al. 2008, 2010, 2011, Pavel et al. 2011). In the initial open-label phase II study conducted at The MD Anderson Cancer Center (Houston, TX, USA), octreotide LAR (30 mg i.m.) with everolimus (5 or $10 \mathrm{mg}$ ), a median PFS of 11.6 months (95\% CI 7.1-16.1), was found (Yao et al. 2008). In another open-label phase II study (RADIANT-1), patients were treated with everolimus in one arm vs a combination of everolimus and octreotide LAR i.m. in the other arm. Median PFS in the everolimus arm was 9.7 and 16.7 months in the everolimus plus octreotide LAR arm (Yao et al. 2010). In another randomized phase III RADIANT-2 study in advanced NETs associated with carcinoid syndrome, it was demonstrated that everolimus plus octreotide LAR provided a clinically meaningful 5.1-month improvement in PFS in this patient population when compared with patients receiving placebo plus octreotide LAR (Pavel et al. 2011). The largest clinical trial, RADIANT-3, was a double-blind, placebo-controlled, randomized phase III study. In this study, everolimus therapy was associated with a 2.4 -fold improvement in median PFS when compared with placebo (11.4 vs 4.6 months; Yao et al. 2011).

The median PFS of our current study was longer when compared with the RADIANT-3 trial (13.1 vs 11.4 months) and shorter when compared with the RADIANT-1 trial (13.1 vs 16.7 months). In the majority of patients (62.5\%), SD was the best response, and PR was observed in $16.7 \%$ of patients. These results are similar to the response rates in the

Published by Bioscientifica Ltd. 
RADIANT-3 study. In this study, SD was achieved in $73 \%$ of patients (Yao et al. 2011). Also in line with the RADIANT trials, a proportion of our patients (58\%) was treated with somatostatin analogs. A potential bias with respect to the ongoing use of somatostatin analogs can, therefore, not be excluded. Together, the results support the clinical relevance and tolerability of everolimus in pNET and potentially in gastrointestinal NETs. Multicenter international trial with everolimus is still ongoing in patients with non-pNETs.

In conclusion, our results for pNET demonstrate that everolimus is an important and safe new drug option, including for those patients who show tumor progression after ${ }^{177} \mathrm{Lu}$-octreotate radionuclide therapy.

\section{Declaration of interest}

B Gumz, F P Costa, D J Kwekkkeboom, and G Kaltsas have no declaration of interest to report. $\mathrm{K}$ Kamp and $\mathrm{W} W$ de Herder received research grants from Novartis.

\section{Funding}

This research did not receive any specific grant from any funding agency in the public, commercial or not-for-profit sector.

\section{Author contribution statement}

All authors collected patients' data and reviewed the manuscript. K Kamp involved in data registry, data analysis, and statistical analysis.

\section{References}

Bergsma H, van Vliet EI, Teunissen JJ, Kam BL, de Herder WW, Peeters RP, Krenning EP \& Kwekkeboom DJ 2012 Peptide receptor radionuclide therapy (PRRT) for GEP-NETs. Best Practice \& Research. Clinical Gastroenterology 26 867-881. (doi:10.1016/j.bpg.2013.01.004)

van Essen M, Krenning EP, Kam BL, de Herder WW, Feelders RA \& Kwekkeboom DJ 2010 Salvage therapy with ${ }^{177}$ Lu-octreotate in patients with bronchial and gastroenteropancreatic neuroendocrine tumors. Journal of Nuclear Medicine 51 383-390. (doi:10.2967/jnumed.109. 068957)

Fraenkel M, Kim MK, Faggiano A \& Valk GD 2012 Epidemiology of gastroenteropancreatic neuroendocrine tumours. Best Practice \& Research. Clinical Gastroenterology 26 691-703. (doi:10.1016/j.bpg.2013.01.006)

Kwekkeboom DJ, de Herder WW, Kam BL, van Eijck CH, van Essen M, Kooij PP, Feelders RA, van Aken MO \& Krenning EP 2008 Treatment with the radiolabeled somatostatin analog $\left[{ }^{177} \mathrm{Lu}^{-D_{O T A}}{ }^{0}, \mathrm{Tyr}^{3}\right]$ octreotate: toxicity, efficacy, and survival. Journal of Clinical Oncology 26 2124-2130. (doi:10.1200/JCO.2007.15.2553)

Modlin IM, Oberg K, Chung DC, Jensen RT, de Herder WW, Thakker RV, Caplin M, Delle Fave G, Kaltsas GA, Krenning EP et al. 2008 Gastroenteropancreatic neuroendocrine tumours. Lancet Oncology 9 61-72. (doi:10.1016/S1470-2045(07)70410-2)

Pavel ME, Hainsworth JD, Baudin E, Peeters M, Hörsch D, Winkler RE, Klimovsky J, Lebwohl D, Jehl V, Wolin EM et al. 2011 Everolimus plus octreotide long-acting repeatable for the treatment of advanced neuroendocrine tumours associated with carcinoid syndrome (RADIANT-2): a randomised, placebo-controlled, phase 3 study. Lancet 378 2005-2012. (doi:10.1016/S0140-6736(11)61742-X)

Rindi G, Kloppel G, Alhman H, Caplin M, Couvelard A, de Herder WW, Eriksson B, Falchetti A, Falconi M \& Komminoth P 2006 TNM staging of foregut (neuro)endocrine tumors: a consensus proposal including a grading system. Virchows Archiv 449 395-401. (doi:10.1007/s00428006-0250-1)

Rindi G, Kloppel G, Couvelard A, Komminoth P, Korner M, Lopes JM, McNicol AM, Nilsson O, Perren A, Scarpa A et al. 2007 TNM staging of midgut and (hind)gut (neuro)endocrine tumors: a consensus proposal including a grading system. Virchows Archiv 451 757-762. (doi:10. 1007/s00428-007-0452-1)

Rinke A, Müller HH, Schade-Brittinger C, Klose KJ, Barth P, Wied M, Mayer C, Aminossadati B, Pape UF, Bläker M et al. 2009 Placebocontrolled, double-blind, prospective, randomized study on the effect of octreotide LAR in the control of tumor growth in patients with metastatic neuroendocrine midgut tumors: a report from the PROMID Study Group. Journal of Clinical Oncology 27 4656-4663. (doi:10.1200/ JCO.2009.22.8510)

Therasse P, Arbuck SG, Eisenhauer EA, Wanders J, Kaplan RS, Rubinstein L, Verweij J, Van Glabbeke M, van Oosterom AT, Christian MC et al. 2000 New guidelines to evaluate the response to treatment in solid tumors. European Organization for Research and Treatment of Cancer, National Cancer Institute of the United States, National Cancer Institute of Canada. Journal of the National Cancer Institute 92 205-216. (doi:10.1093/jnci/92.3.205)

Yao JC, Phan AT, Chang DZ, Wolff RA, Hess K, Gupta S, Jacobs C, Mares JE, Landgraf AN, Rashid A et al. 2008 Efficacy of RAD001 (everolimus) and octreotide LAR in advanced low- to intermediate-grade neuroendocrine tumors: results of a phase II study. Journal of Clinical Oncology 26 4311-4328. (doi:10.1200/JCO.2008.16.7858)

Yao JC, Lombard-Bohas C, Baudin E, Kvols LK, Rougier P, Ruszniewski P, Hoosen S, St Peter J, Haas T, Lebwohl D et al. 2010 Daily oral everolimus activity in patients with metastatic pancreatic neuroendocrine tumors after failure of cytotoxic chemotherapy: a phase II trial. Journal of Clinical Oncology 28 69-76. (doi:10.1200/JCO.2009.24.2669)

Yao JC, Shah MH, Ito T, Lombard-Bohas C, Wolin EM, Van Cutsem E, Hobday TJ, Okusaka T, Capdevila J, de Vries EG et al. 2011 Everolimus for advanced pancreatic neuroendocrine tumors. New England Journal of Medicine 364 514-523. (doi:10.1056/NEJMoa1009290)

Received in final form 12 September 2013

Accepted 13 September 2013

Made available online as an Accepted Preprint

13 September 2013 http://erc.endocrinology-journals.org DOI: $10.1530 / E R C-13-0254$
(C) 2013 Society for Endocrinology Printed in Great Britain
Published by Bioscientifica Ltd. 